\title{
Genetic Parameters for Bud Flushing and Growth Characteristics of White Spruce Seedlings ${ }^{1)}$
}

\author{
By D. M. RweyongezA ${ }^{2), 3)}$, F. C. YeH ${ }^{4)}$ and N. K. DHIR ${ }^{3)}$
}

(Received $7^{\text {th }}$ March 2009)

\begin{abstract}
We estimated heritabilities and correlations for bud flushing and growth traits of white spruce seedlings, and the correlations of seedling traits with 10- and 11year height of the same families in the field. The seedling greenhouse experiment had a randomized complete block design with 30 replications, 58 open-pollinated families and single-tree plots. Individual tree heritability $\left(h_{i}^{2}\right)$ was 0.78 and 0.54 for $18(\mathrm{H} 18)$ and 36 (H36)-week total height, respectively. The corresponding heritabilities for family means $\left(h_{f}^{2}\right)$ were 0.91 and 0.82 . For root collar diameter, $h_{i}^{2}$ were respectively, 0.61 and 0.22 at 24 and 54 weeks from germination. The corresponding $h_{f}^{2}$ were 0.87 and 0.55 . Heritability for bud flushing ranged from 0.13 to $0.46\left(h_{i}^{2}\right)$ and 0.44 to 0.83 $\left(h_{f}^{2}\right)$. The genetic correlation $\left(r_{\alpha}\right)$ between H18 and H36 was 0.70 and that of D24 and D54 was 0.89 , indicating a substantial change in family ranking in one growing season. The type B genetic correlation for H18 with field heights ranged from 0.22 to 0.30 . Type $\mathrm{B}$ genetic correlations of field height with all other seedling traits were very low and largely negative. It can be concluded that: (1) age-age correlation of seedling height can be expected to decline drastically even in a stable environment of the greenhouse, (2) heritability for growth potential is meaningful when estimated on cumulative growth not on individual annual growth increments that are susceptible to short-term environmental variation, (3) dates of bud flushing did not influence variation in height and root collar diameter, and (4) field growth potential is better predicted by greenhouse growth potential than other morphological and shoot phenological traits.
\end{abstract}

Key words: Heritability; genetic correlation; early selection; bud flushing; progeny test.

\section{Introduction}

Genetic studies of tree seedlings in controlled environments provide an opportunity for assessing the genetic variation of growth and phonological traits with limited environmental noises. In these experiments, many morphological, growth, and growth rhythm-related traits can be measured or scored at short regular intervals than would be possible in field progeny and provenance trials. Serial measurements of height and diameter growth allow us to develop growth trajectories of indi-

\footnotetext{
1) Based on the $\mathrm{PhD}$. thesis submitted to the University of Alberta by the first author.

2) Corresponding author: Deogratias M. RWEyongezA. Tel. 780-638-2855, Fax: 780-427-0085, E-Mail: Deogratias. Rweyongeza@gov.ab.ca

3) Reforestation Section, Alberta Sustainable Resource Development, $7^{\text {th }}$ Floor, 9920-108 Street, Edmonton, AB, Canada, T5K $2 \mathrm{M} 4$.

4) Francis C. YEH, Department of Renewable Resources, University of Alberta, Edmonton, AB, Canada T6G 2H1.
}

vidual families and predict their possible effect on future growth of older trees (e.g., RWEYONGEZA et al., 2003). Heritability and genetic correlation from serial measurements show an extent with which genetic variation in quantitative traits is affected by tree age/size (e.g., NiENSTAEDT and RIEMENSCHNEIDER, 1985; YING and MORGEnstern, 1979) and how this could affect decisions on early selection. Variation in the timing of bud flushing and budset has implications on susceptibility of genotypes to frost damage and could also influence variation in annual height growth (e.g., WILKINSON, 1977; LI et al., 1997; O'REILLY and PARKER, 1982).

White spruce (Picea glauca [Moench] Voss) is the most important conifer tree species in Alberta, which makes up $45.9 \%$ by volume of all conifers (AFLW, 1985). Genetic improvement activities in Alberta are centered around improving growth and yield of white spruce and lodgepole pine (Pinus contorta Dougl) as the two major conifers. Thus, understanding the genetics of white spruce at all levels of tree growth and development is essential for the management of the species in the province. This article is part of the large retrospective genetic study of white spruce from the northwest boreal forest in Alberta, which is designed to study genetic variation in juvenile traits in the greenhouse and their possible use as genetic indicators of late growth potential in field experiments.

\section{Materials and Methods \\ Families and Experimental Procedures}

The 58 families involved in the greenhouse study were collected as open-pollinated seedlots from the Peace River region in central and northwestern Alberta, Canada $\left(54^{\circ} 31^{\prime}-58^{\circ} 03^{\prime} \mathrm{N}, 117^{\circ} 35^{\prime}-119^{\circ} 22^{\prime} \mathrm{W}\right.$, and $365-945$ metres above sea level). They were earlier included in the field progeny trial at Chinchaga ( $57^{\circ} 50^{\prime} \mathrm{N}, 118^{\circ} 12^{\prime} \mathrm{W}$ and 470 metres above sea level) and Saddle Hills ( $55^{\circ} 31^{\prime} \mathrm{N}, 119^{\circ} 40^{\prime} \mathrm{W}$ and 914 metres). These field trials have a randomised complete block design with 6 replications and 6-tree row plots at $2.5 \times 2.5$-metre spacing. Both trials were measured for height growth at age ten and eleven years from seeds.

The greenhouse retrospective progeny test was conducted from 1996 to 2000 at the University of Alberta in Edmonton, Canada, to estimate genetic parameters of seedling traits and genetic correlations of seedling traits with advanced age growth of the same families in the field. The greenhouse-field correlations would show the extent with which seedling growth and shoot phenology assessed in controlled environment corresponded with height growth potential in the field. This would in turn reveal the merits of early selection for white spruce in 
the Peace River region. The experimental layout was a randomised complete block design with single-tree plots replicated 30 times. The growth medium was a 2:1 (volume) peat moss to vermiculite mixture with $5.0 \mathrm{~g} \mathrm{~L}^{-1}$ of lime added to maintain the $\mathrm{pH}$ at about 5.0. Seed germination and seedling growth were conducted in the same $700 \mathrm{ml}$ styroblocks. Seedlings were grown at extended photoperiod of $20 \mathrm{hrs} /$ day from a combination of natural and artificial lights. Temperature was maintained at $23^{\circ} \mathrm{C}$ day and night, which is the temperature used to grow white spruce seedlings in Alberta for both operational reforestation and field genetic trials. Seedlings that were used to establish field trials covered in this study were also grown at the same temperature during the greenhouse phase.

The experiment was carried out for three growing seasons of 18 weeks each extending from the first week of May to the last week of August each year. At the end of the first and second growing seasons, seedlings were moved out of the greenhouse in protected sheds for overwintering, which extended from September of the current year to April of the following year. Seedlings were watered once a day and fertilised once a week using the nutrient regime prescribed by the Alberta Tree Improvement and Seed Centre (ATISC), which is the nutrient regime that was used to raise seedlings for the field trials linked to the current study 11 years earlier (see RWEYONGEZA, 2002). The $\mathrm{pH}$ of the growing medium was periodically monitored to maintain it at about 5.0. Many traits were assessed on seedlings (see RWEYONGEZA et al., 2003, 2004, 2006). Traits covered in this article are defined as follows:

H18 - 18-week total seedling height measured at the end of first growing season.

H36 - 36-week total seedling height measured at the end of the second growing season.

HI - second growing season height increment (H36 minus H18).

D24 - 24-week root collar diameter.

D36 - 36-week root collar diameter.

D54 - 54-week root collar diameter.

DI1 - second season root collar diameter increment (D36 minus D24).

DI2 - third season root collar diameter increment (D54 minus D36).

$\mathrm{BL}$ - 36-week average length of the three longest branches.

$\mathrm{NL}$ - average length of 10 randomly picked needles from the oldest branches.

TB2 - date for the terminal bud flushing at the beginning of the second growing season.

BB2 - date for bud flushing on branches at the beginning of the second growing season.

TB3 - date for the terminal bud flushing at the beginning of the third growing season.

BB3 - ate for bud flushing on branches at the beginning of the third growing season.

All heights, root collar diameters, branch and needle length were in millimetres $(\mathrm{mm})$.
To determine the date for bud flushing, terminal bud on the main seedling stem was examined everyday between 3:00 and 5:00 p.m. Bud flushing was considered to have taken place when the bud scale split to expose green needles. The dates for TB2 and TB3 were expressed as the number of days from the date when seedlings were brought back to the greenhouse after overwintering to the date when bud flushing occurred. Because bud flushing on branches involved many buds, BB2 and BB3 were subjectively recorded as the number of days from the date when seedlings were placed in the greenhouse to the date when about $50 \%$ of buds on branches flushed on the same day

\section{Data Analysis}

Prior to the analysis, the data were examined and conformed to the normality and homogeneity of the variance assumptions required for the analysis of variance. The following statistical model was fitted to all traits using the general linear model procedure (PROC GLM) in SAS (SAS INST., 2004):

$$
Y_{i j}=\mu+B_{i}+F_{j}+E_{i j}
$$

where, $Y_{i j}=$ response for $j t h$ family in ith block (replication), $\mu=$ general mean, $B_{i}=$ effect due to ith block, $F_{j}=$ effect due to jth family, $E_{i j}=$ residual for $j$ th family in ith block. Except for the mean, all effects were considered random, with the mean zero and the following variances $\sigma_{b}^{2}$ (block), $\sigma_{f}^{2}$ (family) and $\sigma_{e}^{2}$ (residual). Individual-tree heritability $\left(h^{2}\right)$ and heritability for family means $\left(h_{f}^{2}\right)$ were calculated as follows:

$$
\begin{aligned}
& h_{i}^{2}=\frac{3 \times \sigma_{f}^{2}}{\sigma_{e}^{2}+\sigma_{f}^{2}} \\
& h_{f}^{2}=\frac{\sigma_{f}^{2}}{\left(\sigma_{e}^{2} / k\right)+\sigma_{f}^{2}}
\end{aligned}
$$

where, $k$ is average number of seedlings per family, and variance components are as previously defined. White spruce is self-fertile and inbred seedlings do not exhibit inbreeding depression until later in life (FOWLER and PARK, 1983; PARK et al., 1984). Therefore, 3 instead of 4 was applied as the coefficient of relationship to calculate the additive genetic variance from $\sigma_{f}^{2}$ considering that seedlings might have been a mixture of half- and fullsibs. Standard errors for $h^{2}{ }_{i}$ and $h^{2}$ were calculated as described by BECKER (1975) and WRIGHT (1976), respectively. The genetic correlation $\left(r_{a}\right)$ was calculated as follows:

$$
r_{a}=\frac{\sigma_{f_{x y}}}{\sigma_{f_{x}} \times \sigma_{f_{y}}}
$$

where $\sigma_{f_{x y}}$ is the family covariance between $x$ and $y, \sigma_{f_{x}}$ and $\sigma_{f_{y}}$ are square roots of the family variance components for trait $x$ and $y$, respectively. Standard errors for the genetic correlations were calculated as described by ROBERTSON (1959). The phenotypic correlation was calculated from individual seedling values using PROC CORR in SAS. The Pearson's correlation coefficient 
was used to examine the relationship between family mean performance with latitude, longitude and elevation at the place of seed origin. Although these families were sampled without a stand structure, these correlations would indicate whether or not geographic clines for shoot phenology and juvenile growth exist in the region. The type B genetic correlation calculated as described by ROBERTSON (1959) was used to determine the extent of rank correspondence between performance of seedling families in the greenhouse and 10(H10) and 11- (H11) year old trees from the same seedlots in the two field trials. This correlation was computed as follows:

$$
r_{b}=\frac{m s_{f}-m s_{s f}}{m s_{f}+m s_{s f}-2 \times m s_{e}}
$$

where, $r_{b}$ is type B genetic correlation, $m s_{f}, m s_{f s}$ and $m s_{e}$ are mean squares for family, site $\mathrm{x}$ family and error, respectively, from the analysis of variance combining greenhouse and field trial data. In this case, the greenhouse and field trial are treated as different test sites (environments). Before performing the analysis of variance, greenhouse and field trial data were separately standardized by subtracting the mean from individual tree values and dividing by the standard deviation. In this case, the resulting data have the mean of zero and variance of 1.0, which allow them to be compared across the two testing environments, even though trees differed in size and ages. The standard error for $r_{b}$ was also approximated according to Robertson (1959) as follows;

$$
S E\left(r_{b}\right) \approx \sqrt{\frac{\left[1+n t\left(1-r_{b}^{2}\right)\right]^{2}+r_{b}^{2}}{(N-1) n^{2} t^{2}}}
$$

where $S E\left(r_{b}\right)$ is standard error of $r_{b} ; N$ is the number of families, $n$ is the number of trees per family; and $t$ is intraclass correlation, which is $1 / 3$ of individual family heritability across site.

\section{Results and Discussion}

\section{Family Mean Performance}

Table 1 shows that on average TB2 and BB2 respectively, occurred approximately 8 (7.7) and 8 (7.5) days from the start of the growing season. On average, there was a 2 -day difference between TB3 ( $\approx 11$ days $)$ and BB3 ( $\approx 9$ days). Bud flushing during the third growing season took 3 (TB3) and 1 (BB3) days longer than the corresponding bud flushing during the second growing season. The range of bud flushing date for individual seedlings was $4-16$ days (TB2), $4-15$ days (BB2), $5-21$ (TB3) and $5-19$ (BB3). Therefore, the date for bud flushing was shorter and more uniform during the second than the third growing season.

The differences in the pattern of bud flushing during the second and third growing seasons may be explained by the condition of the seedlings after over-wintering. Temperature and seedling nutrition hasten bud flushing and delay budset (MURRAY, 1994; HowE et al., 2003). In this study, seedlings were grown at the same nutrient, moisture, light and temperature regimes in all three growing seasons. However, seedlings were visually greener and more vigorous at the start of the second than the third growing season. During the first overwintering, the November 1996 - April 1997 period was cooler than the same period during the second over-wintering (November 1997 - April 1998). According to ENVIRONMENT CANADA (2006), the Edmonton City Centre average temperatures for November and December 1996 were, respectively, $-12.3^{\circ} \mathrm{C}$ and $-17.7^{\circ} \mathrm{C}$. The corresponding temperatures for 1997 were $-2.1^{\circ} \mathrm{C}$ and $-3.7^{\circ} \mathrm{C}$. January and February of 1997 and 1998 had approximately similar average temperatures. March and April of 1997 had average temperature of $-7.7^{\circ} \mathrm{C}$ and $1.7^{\circ} \mathrm{C}$, respectively, and the corresponding values for 1998 were $-3.8^{\circ} \mathrm{C}$ and $6.9^{\circ} \mathrm{C}$. Overall, the average temperatures for the first and second over-wintering

Table 1. - Mean ( \pm standard error), range of family means (in parentheses), variance components $(\%$ of the total variance) and heritability ( \pm standard error) estimates for seedling traits.

\begin{tabular}{lcccccccccc}
\hline Trait & Mear & $\sigma_{e}^{2}$ & $\sigma_{f}^{2}$ & $\mathrm{~F}$ & $\mathrm{P}>\mathrm{F}$ & $\sigma_{f}^{2}$ & $\mathrm{~F}$ & $\mathrm{P}>\mathbf{F}$ & $h_{i}^{2}$ \\
\hline H18 & $109.0 \pm 2.1(80.6-160.6)$ & 70.3 & 4.7 & 4.77 & 0.0001 & 24.9 & 11.26 & 0.0001 & $0.78 \pm 0.12$ & $0.91 \pm 0.22$ \\
I136 & $199.5 \pm 4.5(121.5-320.3)$ & 77.8 & 5.1 & 3.68 & 0.0001 & 17.1 & 5.70 & 0.0001 & $0.54 \pm 0.10$ & $0.82 \pm 0.16$ \\
H1 & $88.1 \pm 3.1(38.6-166.9)$ & 83.4 & 5.4 & 3.65 & 0.0001 & 11.2 & 0.65 & 0.0001 & $0.36 \pm 0.08$ & $0.74 \pm 0.13$ \\
BL & $87.9 \pm 1.9(51.7-124.5)$ & 79.2 & 1.8 & 2.13 & 0.0005 & 18.9 & 7.01 & 0.0001 & $0.58 \pm 0.10$ & $0.86 \pm 0.18$ \\
NL & $12.2 \pm 0.1(10.4-14.8)$ & 76.5 & 2.1 & 2.46 & 0.0001 & 21.4 & 8.52 & 0.0001 & $0.66 \pm 0.11$ & $0.88 \pm 0.19$ \\
D24 & $2.2 \pm 0.1(1.5-3.6)$ & 74.5 & 6.4 & 5.22 & 0.0001 & 19.1 & 7.56 & 0.0001 & $0.61 \pm 0.11$ & $0.87 \pm 0.18$ \\
D36 & $3.7 \pm 0.1(2.3-5.5)$ & 81.9 & 3.8 & 3.31 & 0.0001 & 14.3 & 5.45 & 0.0001 & $0.45 \pm 0.09$ & $0.82 \pm 0.15$ \\
D54 & $6.5 \pm 0.2(4.3-9.0)$ & 90.2 & 2.6 & 1.84 & 0.0047 & 7.3 & 2.24 & 0.0001 & $0.22 \pm 0.07$ & $0.55 \pm 0.09$ \\
IT1 & $1.4 \pm 0.0(0.7-2.0)$ & 86.9 & 4.7 & 3.65 & 0.0001 & 8.4 & 3.47 & 0.0001 & $0.27 \pm 0.06$ & $0.71 \pm 0.11$ \\
DI2 & $2.5 \pm 0.1(0.9-4.1)$ & 93.2 & 2.0 & 1.60 & 0.0240 & 4.8 & 1.77 & 0.0006 & $0.15 \pm 0.06$ & $0.44 \pm 0.08$ \\
TB2 & $7.7 \pm 0.1(5.9-9.8)$ & 81.6 & 3.5 & 3.21 & 0.0001 & 14.9 & 5.92 & 0.0001 & $0.46 \pm 0.09$ & $0.83 \pm 0.16$ \\
BB2 & $7.5 \pm 0.1(5.9-9.3)$ & 82.0 & 3.6 & 3.25 & 0.0001 & 14.5 & 5.75 & 0.0001 & $0.45 \pm 0.09$ & $0.83 \pm 0.15$ \\
TB3 & $10.7 \pm 0.2(7.7-14.2)$ & 85.6 & 4.7 & 1.77 & 0.0092 & 9.6 & 1.86 & 0.0004 & $0.30 \pm 0.12$ & $0.46 \pm 0.11$ \\
BB3 & $9.2 \pm 0.1(8.1-10.7)$ & 93.5 & 2.2 & 1.76 & 0.0082 & 4.3 & 1.79 & 0.0004 & $0.13 \pm 0.06$ & $0.44 \pm 0.08$ \\
\hline
\end{tabular}

H18 and H36 height at age 18 and 36 weeks; HI - height increment (H36 minus H18); BL - 36-week branch length; NL - 36-week needle length; D24, D36 and D54 - root collar diameter at age 24, 36 and 54 weeks; DI1 - diameter increment (D36 minus D24); DI2 - diameter increment (D54 minus D24); TB2 and BB2 - terminal and branch bud flushing at the beginning of the second growing season; TB3 and BB3 - terminal and branch bud flushing at the beginning of the third growing season; $\sigma_{e}^{2}$, $\sigma_{b}^{2}$ and $\sigma_{f}^{2}$-variances for residual, block and family; $h_{i}^{2}$-individual-tree heritability, $h_{i}^{2}$-heritability for family means. 
period were, $-9.7^{\circ} \mathrm{C}$ and $-4.6^{\circ} \mathrm{C}$, respectively. Because over-wintering took place in an open space outside the greenhouse where temperature could not be controlled, winter respiration and depletion of nutrient reserves from the seedlings may have been higher during the second than the first over-wintering period. Nutrient reserves affect root growth after cold storage, which in turn affect hydration of seedlings, cell expansion and bud flushing (see WANG and ZWIAZEK, 1999a, 1999b; JIANG et al., 1994). Therefore, seedlings were physiologically, better suited to initiate shoot elongation at the beginning of the second than the third growing season. This could also account for a sporadic nature of the third season bud flushing.

Although all growing seasons had the same lengths, on average, seedlings grew more during the first (H18) than the second (HI) growing season by $23.7 \%$ (Table 1 ). In temperate conifer tree seedlings, the first and second growing seasons are characterised by free and fixed growth, respectively (DOAK, 1935; LANNER, 1976). During the first growing season, shoot elongation continued to the end of August, whereas during the second season shoot elongation ceased in the first week of August. Therefore, different modes of shoot growth may be responsible for large differences between the first and second season height increments. Early cessation of shoot elongation during the second season may have taken place once the predetermine number of stem components became fully elongated.

\section{Variation for Bud Flushing}

Table 1 shows that variation among families for bud flushing was significant $(P \leq 0.05)$. Heritabilities were higher for bud flushing at the beginning of the second (TB2 and BB2) than the third (TB3 and BB3) growing seasons. For example, estimates of $h^{2}{ }_{i}$ and $h^{2}{ }_{f}$ for TB3 was respectively $68.9 \%$ and $56.6 \%$ of the corresponding heritability values for TB2. In addition, TB2 and BB2 had approximately the same heritability, whereas $h_{i}^{2}$ for BB3 was only $41.9 \%$ of the corresponding value for TB3. Table 2 shows that in the third growing season, differences in the date for bud flushing among seedlings within family increased substantially (large $\sigma_{e}^{2}$ ), especially for TB3 leading to low estimated heritability.

Bud flushing and bud set are the most commonly assessed shoot phenological traits. Studies show that these traits exhibit high heritability (see Howe et al., 2003). For example, in Norway spruce (Picea abies (L.) Kharst.), heritability for bud flushing was $0.42-0.65$ for seedlings subjected to three levels of moisture stress treatments (SONESSON and ERIKSSON, 2003). In addition, in Norway spruce, heritability for bud flushing was 0.52-0.59 in a treatment combining high temperature and high or low moisture, and $0.20-0.26$ in a treatment combining low temperature and high or low moisture (SONESSON et al., 2002). In field trials of Norway spruce, $h^{2}{ }_{i}$ of $0.75-0.89$ and $h^{2}$ of $0.78-0.87$ for bud flushing were found by HANNERZ et al. (1999). Thus, high heritability for bud flushing observed for the second growing season in the present study are consistent with what has been found in other conifers.

\section{Variation for Seedling Growth Traits}

Heritability for height declined sharply from $0.79 \pm$ $0.12\left(h_{i}^{2}\right)$ and $0.91 \pm 0.22\left(h_{f}^{2}\right)$ at the end of the first growing season (H18) to $0.54 \pm 0.10\left(h^{2}\right)$ and $0.83 \pm 0.16$ $\left(h_{f}^{2}\right)$ and the end of the second growing season (H36). This was largely due to the increase in height growth differences among seedlings within family as indicated by a $10.8 \%$ increase in the percentage of the residual $\left(\sigma_{e}^{2}\right)$ variance (H18 vs. H36). Likewise, $h^{2}$ for the second season height increment (HI) was only $45.6 \%$ of the corresponding heritability for the first season height increment (H18) largely due to an $18.8 \%$ increase in the percentage of the residual variance (H18 vs. HI).

Table 1 shows that $h^{2}$ for root collar diameter declined almost constantly between age 24 (D24) and 54 (D24) weeks. Like height, root collar diameter increment during the second growing season (DI1) had higher heritability than the third season increment (DI2). Heritability for 36-week branch length (BL) was slightly higher than the corresponding heritability for H36 and D36, but reasonably within the range of H36 (Table 1). Because branch length was assessed once, its variation trend could not be established in this study. However, judging from the heritability of height and root collar diameter, variation in growth among families became increasingly environmental, as seedlings grew older.

The age pattern of change in heritability for growthrelated traits observed in the present study has also been observed in other species such as lodgepole pine in Alberta (Pinus contorta Dougl.) (Wu et al., 1995), Scotch pine (Pinus sylvestris L.) under dense and wide spacing (JANSSON et al., 1998; Jonsson et al., 2000), Norway spruce (Picea abies (L.) Kharst) seedlings subjected to different watering regimes (SONESSON and ERIKSSON, 2003) and in Norway spruce grown for two growing seasons (MARI et al., 2003). This shows that heritabilities of juvenile growth traits are most likely to fluctuate drastically even in stable growing environments such greenhouses and growth chambers. Family variation in seed size may influence variation in juvenile height (Wennstrom et al., 2002). This would cause heritability for growth traits to decline as the influence of seed size on height growth declines. In the present study, Pearson's correlation of family means for H18 and H36 with 1000 -seed weight was respectively, 0.42 and 0.43 $(P \leq 0.001)$. Because heritability for height declined considerably (H18 vs. H36) while the correlation between seed weight and height remained unchanged, variation in seed size may not have substantially influenced variation in seedling growth.

Table 1 shows that variation in needle length (NL) was highly heritable with $h^{2}{ }_{i}$ and $h^{2}$ estimates exceeding corresponding values for all traits assessed during the second growing season. RWEYONGEZA et al. (2003) found low $h^{2}{ }_{i}(0.16-0.27)$ and moderate $h_{f}^{2}(0.42-0.52)$ at three field trials of Scotch pine from central Siberia planted in Alberta, Canada. Variation in needle length has hardly been studied

\section{Correlations for Seedling Traits}

Table 2 presents genetic $\left(r_{a}\right)$, phenotypic $\left(r_{p}\right)$ and Pearson's correlation coefficient for family means $\left(r_{f}\right)$ between 
Table 2. - Correlation coefficients between seedling traits in the greenhouse. Trait definitions appear in Table 1.

\begin{tabular}{lccc}
\hline Trait Pair & $r_{\alpha}$ & $r_{p}$ & $r_{f}$ \\
\hline H18 \& H36 & $0.70 \pm 0.06$ & $0.65(0.0001)$ & $0.81(0.0001)$ \\
H18 \& HI & $0.50 \pm 0.10$ & $0.32(0.0001)$ & $0.51(0.0001)$ \\
III \& II36 & $0.90 \pm 0.03$ & $0.93(0.0001)$ & $0.91(0.0001)$ \\
H36 \& D36 & $0.89 \pm 0.03$ & $0.83(0.0001)$ & $0.81(0.0001)$ \\
D24 \& D54 & $0.89 \pm 0.04$ & $0.89(0.0001)$ & $0.75(0.0001)$ \\
D36 \& D54 & $0.59 \pm 0.12$ & $0.84(0.0001)$ & $0.84(0.0001)$ \\
II36 \& TB2 & $-0.01 \pm 0.14$ & $0.09(0.0014)$ & $-0.03(0.8358)$ \\
H18 \& TB2 & $-0.05 \pm 0.12$ & $0.07(0.0033)$ & $-0.04(0.7484)$ \\
H1 \& TB2 & $-0.01 \pm 0.15$ & $0.05(0.0617)$ & $-0.00(0.9786)$ \\
D36 \& TB2 & $0.09 \pm 0.14$ & $0.16(0.0001)$ & $0.14(0.2936)$ \\
DI1 \& TB2 & $-0.02 \pm 0.15$ & $0.07(0.0111)$ & $0.05(0.7150)$ \\
BL \& TB2 & $-0.18 \pm 0.13$ & $0.00(0.9937)$ & $-0.13(0.3222)$ \\
NL \& TB2 & $0.12 \pm 0.13$ & $0.09(0.0006)$ & $0.13(0.3372)$ \\
H18 \& NL & $0.47 \pm 0.09$ & $0.28(0.0001)$ & $0.47(0.0002)$ \\
II36 \& NL & $0.66 \pm 0.07$ & $0.47(0.0001)$ & $0.60(0.0001)$ \\
H1 \& NL & $0.73 \pm 0.07$ & $0.44(0.0001)$ & $0.58(0.0001)$ \\
D36 \& NL & $0.56 \pm 0.09$ & $0.47(0.0001)$ & $0.55(0.0001)$ \\
D54 \& NL & $0.33 \pm 0.15$ & $0.38(0.0001)$ & $0.39(0.0024)$ \\
BL \& NL & $0.53 \pm 0.09$ & $0.41(0.0001)$ & $0.51(0.0001)$ \\
\hline
\end{tabular}

$r_{a}$-genetic correlation; $r_{p}$-phenotypic correlation; $r_{f}$-Pearson's correlation for family means.

seedling traits assessed in the greenhouse. The correlations between $\mathrm{H} 18$ and $\mathrm{H} 36$ and those between D24, D36 and D54 are age-age correlations designed to measure the stability of family ranking between ages. The correlation between H18 and H36 $\left(r_{\alpha}=0.70 \pm 0.06\right)$ could be considered low for the same trait assessed only one year apart. A much low correlation $\left(r_{a}=0.45 \pm 0.10\right)$ existed between 2- (H2) and 36-week (H36) seedling height (RweyongezA, 2002). Such large declines in the genetic correlation over a short period suggest that early seedling height growth may not be a reliable indicator of family superiority for order trees. The low $r_{a}$ between $\mathrm{H} 18$ and $\mathrm{HI}$ is also partly responsible for the low correlation between $\mathrm{H} 18$ and H36. The genetic correlation between D24 and D54 was high $\left(r_{a}=0.89 \pm 0.04\right)$ suggesting that family ranks based on root collar diameter could be more stable than ranks based on seedling height. Height (H36) and diameter (D36) were highly correlated $\left(r_{a}=0.89 \pm 0.03\right)$ suggesting that selection for growth potential could be equally based on height or root collar diameter. It also shows that selecting for height growth will alter diameter growth, because the two traits are controlled by similar growth processes.

Table 2 shows that the correlation for needle length (NL) with height, diameter and branch length was low to moderate $\left(r_{a}=0.33 \pm 0.15-0.73 \pm 0.07\right)$. This suggests that the causal relationship between needle length and growth-related traits may be weak. In Scotch pine, RWEYONGEZA et al. (2003) found a moderate negative genetic $\left(r_{a}=-0.56 \pm 0.19\right)$ and a low positive phenotypic $\left(r_{p}=0.27\right)$ correlation between needle length and 6-year height. The phenotypic correlation at the other two sites 
was 0.27 and 0.13 , whereas $r_{a}$ was almost non-existent considering the size of the standard error. Conifer tree needles have a lifespan of 2-3 years, whereas tree height and diameter growth is indeterminate over many decades. Consequently, genetic parameters and genotypic ranking for needle length can be inferred with certainty in few years of indoor or field progeny testing, whereas height and diameter cannot. If genetic variation for needle length correlated well with genetic variation for height and diameter, NL could be a useful early selection indicator.

Table 2 shows that the correlation for bud flushing exemplified by TB2 with growth-related traits was nonexistent at a genetic $(-0.18 \pm 0.13$ to $0.12 \pm 0.13)$ and phenotypic level. The period between bud flushing and bud set constitutes the length of height growing season. Because the dates for bud sets were not monitored in this study, the correlation between growth potential and growth duration could not be established. To safeguard trees against late spring frost and early fall frost, superior growth potential should be independent of shoot phenology and duration of the growing season. Earlier studies of white spruce indicated that growth potential was related to shoot phenology and length of growing season. For example, WILKINSON (1977) recorded the date for bud flushing in white spruce families for two consecutive years. The correlation between annual leader length and the date of bud flushing was -0.69 and -0.94 , which indicates that families that delayed bud flushing had lower annual height increment than those that opened buds earlier. Using white spruce seed orchard clones, O'REILLY and PARKER (1982) found that annual leader length was positively correlated $\left(r_{a}=0.59\right)$ with the duration of the growing season. White spruce provenances with early bud flushing and late bud set had better height growth than provenances with late bud flushing and early budset (Li et al., 1997). In other conifers, SONESSON and ERIKSSON (2003) observed low correlation $\left(r_{a}=0.44\right)$ between the time for bud flushing and its associated second growing season height increment in Norway spruce. LI et al. (1993) on the other hand found that white spruce height growth increment was more correlated with the rate $\left(r_{a}=0.74\right)$ than the duration $\left(r_{\alpha}=36\right)$ of growth. Generally, these cited studies suggest that height growth superiority may be moderately dependent on the length of the growing season.

Table 3. - Correlation between seedling traits and geographic variables of seed origin. Trait definitions appear in Table 1.

\begin{tabular}{lllllllll}
\hline & $\mathrm{H} 18$ & $\mathrm{H} 36$ & $\mathrm{D} 36$ & $\mathrm{D} 54$ & $\mathrm{BL}$ & $\mathrm{NL}$ & $\mathrm{TB} 2$ & $\mathrm{~TB} 3$ \\
\hline Lalitude & -0.17 & -0.22 & -0.22 & -0.11 & -0.14 & $-0.38^{* *}$ & -0.04 & -0.06 \\
Longitude & -0.14 & -0.25 & -0.23 & -0.24 & -0.07 & -0.10 & -0.11 & -0.09 \\
Elevation & -0.14 & -0.05 & -0.01 & -0.05 & -0.08 & -0.07 & 0.13 & 0.08 \\
\hline
\end{tabular}

** $-P=0.0035$. All other correlations are not significant $(P>0.05)$.

Table 4. - Type B genetic correlation coefficients between seedling traits and field heights. Seedling trait definitions appear in Table 1.

\begin{tabular}{lcccc}
\hline & AH10 & AH1 & BH10 & BH11 \\
\hline H18 & $0.30 \pm 0.15$ & $0.29 \pm 0.15$ & $0.23 \pm 0.20$ & $0.20 \pm 0.23$ \\
H36 & $0.10 \pm 0.17$ & $0.06 \pm 0.18$ & $0.17 \pm 0.22$ & $0.15 \pm 0.26$ \\
HI & $-0.02 \pm 0.17$ & $-0.08 \pm 0.17$ & $-0.05 \pm 0.22$ & $-0.05 \pm 0.25$ \\
D24 & $0.03 \pm 0.15$ & $-0.02 \pm 0.15$ & $-0.12 \pm 0.20$ & $-0.12 \pm 0.23$ \\
D36 & $-0.04 \pm 0.16$ & $-0.08 \pm 0.16$ & $-0.11 \pm 0.20$ & $-0.10 \pm 0.24$ \\
D54 & $-0.22 \pm 0.16$ & $-0.27 \pm 0.15$ & $-0.35 \pm 0.19$ & $-0.37 \pm 0.21$ \\
BL & $0.11 \pm 0.16$ & $0.08 \pm 0.16$ & $0.25 \pm 0.20$ & $0.22 \pm 0.23$ \\
NL & $0.16 \pm 0.16$ & $0.11 \pm 0.16$ & $0.11 \pm 0.22$ & $0.11 \pm 0.25$ \\
TB2 & $0.08 \pm 0.18$ & $0.11 \pm 0.18$ & $0.06 \pm 0.24$ & $0.08 \pm 0.27$ \\
TB3 & & & & \\
\hline
\end{tabular}

AH10 and AH11 - total height at age 10 and 11 years at site A, respectively; $\mathrm{BH} 10$ and $\mathrm{BH} 11$ - total height at age 10 and 11 years at site $\mathrm{B}$, respectively. 


\section{Correlations with Seed Origin}

Table 3 shows that growth traits and shoot flushing were weakly negatively correlated with latitude $(r=-0.34$ to -0.04$)$, longitude $(r=-0.25$ to -0.07$)$ and elevation $(r=-0.14$ to -0.01$)$ of seed origin. Although these correlations were significantly low $(P>0.05)$, they showed that growth potential would decline with an increase in latitude and elevation of seed origin, which has been demonstrated in white spruce for the same region using provenances sampled from a broader geographic region in Alberta (see RWEYONGEZA et al., 2007). Because families used in the present study are of narrow latitudinal range, low but negative correlations (Table 3) are consistent with our expectations. The tendency for high latitudes and continental trees to open buds earlier than trees from low latitudes and maritime climates was demonstrated in many Pinus species by STEINER (1979). Thus, although the correlation between TB2 and latitude (Table 3 ) is very low, the negative correlation between the two variables is the more likely possibility with adequate latitudinal sampling.

\section{Greenhouse-Field Correlations}

The genetic correlations for 10- and 11-year heights at two field sites with seedling traits in the greenhouse were very low with high standard errors (Table 4). The highest correlation was between $\mathrm{H} 18$ and height at Chinchaga (site A), which was $0.30 \pm 0.15$ (AH10) and $0.29 \pm 0.15$ (AH11). For height and root collar diameter, the greenhouse-field correlation declined with seedling age, and the correlation between root collar diameter with field height became increasingly negative, as seedlings grew older. Considering the size of the standard errors, these correlations are too low to have practical significance. In Norway spruce, date for bud flushing was slightly negatively genetically correlated with 24-year field volume (SONESSON et al., 2002). In addition, in Norway spruce, different stages of bud flushing were slightly negatively correlated genetically with 9-14-year field height (HANNERZ et al., 1999). Thus, lack of strong greenhouse-field correlation observed in this study is consistent with what has been observed in other spruce trials.

\section{Conclusions}

Indoor experiments provide an opportunity for multiple assessments of the same traits at different ages in a relatively stable environment. These assessments allow us to examine changes in the magnitude of genetic parameters of growth traits, which are caused by changes in tree age and size with a minimum influence of seasonal variation in growth conditions. From the results of the present study of white spruce families in the Peace River region of Alberta, we can make the following conclusions: (1) heritability for bud flushing and growth (height and diameter) traits is high but vulnerable to large changes seasonally, even in the stable conditions of the greenhouse. Thus, practical conclusions derived from seedling experiments should be collaborated with prolonged field testing. (2) The correlation between shoot phenology and annual height growth appears to be nonexistent, at least when phenology is assessed only as a date for initiation of shoot elongation. However, this does not preclude the dependence of annual growth on the length of the growing season unless both the dates for bud flushing and bud set are assessed. (3) The retrospective genetic correlation between traits of seedlings in the greenhouse and height growth of older trees in field trials appears to be too low to have practical significance. This could be partly due to ontogenetic differences between the two sets of trees and the differences in the environments in which they are growing.

\section{Acknowledgements}

We thank the Alberta Tree Improvement and Seed Centre (ATISC) for its technical advice on growing white spruce seedlings and for providing field measurement data; the greenhouse staff at the Department of Agricultural, Food and Nutritional Science at the University of Alberta; and the anonymous referee for critical and constructive comments. Funding for this research was provided by Manning Diversified Forest Products to FCY.

\section{References}

BECKER, W. A. (1975): Manual of Quantitative Genetics. Washington State University Press, Pullman.

DoAK, C. C. (1935): Evolution of foliar types, dwarf shoots, and cone scales of Pinus. Illinois Biolog. Monogr. 13: $1-163$.

Fowler D. P. and S. Y. PARK (1983): Population studies of white spruce. Effects of self-pollination. Can. J. For. Res. 13: 1133-1138.

HANNerz, M., J. Sonesson and I. EkBerg (1999): Genetic correlations between growth and growth rhythm observed in a short-term test and performance in longterm field trials of Norway spruce. Can. J. For. Res. 29: 768-778.

Howe, G. T., S. N. Aitken, D. B. Neale, K. D. Jermstad, N. C. Wheeler and T. H. H. Chen (2003): From genotype to phenotype: unravelling the complexities of cold adaptation in forest trees. Can. J. Bot. 81: 1247-1266.

Jansson, G. A. Jonsson and E. Gosta (1998): Efficiency of early testing in Pinus sylvestris L. grown under two different spacing in a growth chamber. Silvae Genet. 47. 298-306.

JiAnG, Y., J. J. ZwiazeK and E. S. Macdonald (1994): Effect of prolonged cold storage on carbohydrate and protein content and field performance of white spruce bareroot seedlings. Can. J. For. Res. 24: 1369-1375.

Jonsson, A., E. GostA., Z. YE and F. F. YEH (2000): A retrospective early test of Pinus sylvestris seedlings grown at a wider and dense spacing. Ca. J. For. Res. 30: 1443-1452.

LANNER, R. M. (1976): Patterns of shoot development in Pinus and their relationship to growth potential, pp 223-243. In: Tree Physiology and Yield Improvement, edited by M. G. R. CANNELL and F. T. LAST), Academic Press. London/UK.

Li, P., J. Beaulieu and J. Bousquet (1997): Genetic structure and pattern of genetic variation among populations in eastern white spruce (Picea glauca). Can. J. For. Res. 27: 189-198.

Li, J., J. Beaulieu, A. Corrieau and J. Bousquet (1993): Genetic variation in juvenile growth and phenology in a white spruce provenance-progeny test. Silvae Genet. 42: 52-60. 
MARI, S., G. JANSSON and A. JONSSON. (2003): Genetic variation in nutrient utilization and growth traits in Picea abies seedlings. Scand. J. For. Res. 18: 19-28.

Murray, M. B., R. I. Smith, I. D. Leith, D. Fowler, H. S. LEE, D. A. FRIEND and P. G. JARVIS (1994): Effect of $\mathrm{CO}_{2}$, nutrition and climatic warming on bud phenology in Sitka spruce (Picea sitchensis) and their impact on the risk of frost damage. Tree Physiol. 14: 691-706.

Niestaedt, H and. E. Riemenschneider. (1985): Changes in heritability estimates with age and site in white spruce, Picea glauca (Moench) Voss. Silvae Genet. 34: 34-41.

PARK, S. Y., D. P. Fowler and J. F. Coles (1984): Population studies of white spruce. II. Natural inbreeding and relatedness among neighbouring trees. Can. J. For. Res. 14: 909-913.

ROBERTSON, A. (1959): The sampling variance of the genetic correlation coefficient. Biometrics 15: 469-485.

RWEYONGEZA, D. M. (2002): Genetic analysis of seasonal seedling height growth curves and early selection in white spruce seedlings. $\mathrm{PhD}$ Thesis submitted to the University of Alberta, Edmonton, Canada.

Rweyongeza, D. M., F. C. Yeh, B. P. DanciK and N. K. DHIR (2003): Genetic variation in height, branch and needle lengths of Pinus sylvestris L. from Siberia tested in Alberta, Canada. Silvae Genet. 52: 52-60.

Rweyongeza, D. M., R-C. YAng., N. K. DhiR. L. K. BARNHARDT and C. HANSEN. (2007): Genetic variation and climatic impacts on survival and growth of white spruce in Alberta, Canada. Silvae Genet. 56: 117-127.

SAS InstiTUTE (2004): SAS System for Windows. Version 9.1. Carry, NC.

Sonesson, J. and E. Gosta (2003): Genetic variation in drought tolerance in Picea abies seedlings and its relationship to growth in controlled and field environments. Scand. J. For. Res. 18: 7-18.
SONESSON, J., J. GunNAR and E. Gosta (2002): Retrospective genetic testing of Picea abies under controlled temperature and moisture regimes. Can. J. For. Res. 32: 81-91.

SteineR, K. G. (1979): Patterns of variation in bud-burst among populations in several Pinus species. Silvae Genet. 28: 185-194.

WANG, Y. and J. J. ZWIAZEK (1999a): Effect of early spring photosynthesis on carbohydrate content, bud flushing and root and shoot growth of Picea glauca bareroot seedlings. Scand. J. For. Res. 14: 295-302.

WANG, Y. and J. J. ZWIAZEK (199B): Effect of storage temperature on physiological characteristics of fall-lifted white spruce (Picea glauca) bareroot seedlings. Can. J. For. Res. 29: 679-686.

Wennstrom, U., U. Bergsten and J-E. Nilsson (2002): Effects of seed weight and seed type on early seedling growth of Pinus sylvestris under harsh and optimal conditions. Scand. J. For. Res. 17: 118-130.

WiLKINSON, R. C. (1977): Inheritance of budbreak and correlation with early height growth in white spruce (Picea glauca) from New England. US For. Ser. Res. Pap. NE391.

WRIGHT, J. W. (1976): Introduction to Forest Genetics. Academic Press, New York.

Wu, H. X., F. C. Yeh, R. P. Pharis, B. P. Dancik, I. B. JiANG, I. DyMock and N. K. DHIR (1995): Genetic parameters of greenhouse growth and performance of 2-year Pinus contorta subsp. latifolia. Scand. J. For. Res. 10: 12-21.

Ying, C. C. and E. K. Morgenstern. (1979): Correlations of height growth and heritabilities at different ages in white spruce. Silvae Genet. 28: 181-185.

\title{
Population Differentiation and Climatic Adaptation for Growth Potential of White Spruce (Picea glauca) in Alberta, Canada
}

\author{
By D. M. RweyongezA ${ }^{1)}$, L. K. Barnhardt, N. K. Dhir and C. Hansen \\ Reforestation Section, Alberta Sustainable Resource Development, \\ $7^{\text {th }}$ Floor, 9920-108 Street, Edmonton, AB, Canada, T5K 2M4
}

(Received $9^{\text {th }}$ March 2009)

\begin{abstract}
Genetic differentiation among white spruce populations in Alberta, Canada, was studied using time series data of height and diameter and a climatic index developed by principal component analysis. The objectives were to discern patterns of variation for growth poten-

\footnotetext{
1) Corresponding author: Deogratias M. Rweyongeza. Tel. 780 638-2855, Fax: 780-427-0085. Email: Deogratias.Rweyongeza@ gov.ab.ca
}

tial and predicted optimum climate; compare optimum climate between populations, between height and diameter at the same age and between height or diameter at different ages; and to see if optimum climate differed from the climate inhabited by populations. Using cluster analysis we found that: (1) populations from mid-latitudes $\left(54^{\circ}-57^{\circ} \mathrm{N}\right)$ and mid-elevations $(600-800 \mathrm{~m})$ were grouped together and exhibited high growth potential; populations from north of $57^{\circ} \mathrm{N}$ were grouped with those from elevations higher than $900 \mathrm{~m}$ in the Rocky 